\title{
Electrochemical Determination of Caffeine in Oolong Tea Based on Polyelectrolyte Functionalized Multi-Walled Carbon Nanotube
}

Yan Zhang ${ }^{\#}$, Jin Shang ${ }^{\#}$, Bo Jiang, Xianrong Zhou* and Jianhua Wang *

College of Life Science and Technology, Yangtze Normal University, Chongqing, 408100, P. R. China ${ }^{\#}$ These authors contribute equally

*E-mail: zhouxianrong@yznu.cn; wangjianhua@yznu.cn

doi: $10.20964 / 2017.03 .02$

Received: 1 December 2016 / Accepted: 29 December 2016 / Published: 12 February 2017

In the present work, a voltammetric sensor for detection of caffeine was prepared by modifying a glassy carbon electrode with Nafion and PDDA-MWCNT. This sensor shows high sensitivity for caffeine determination in the range from 0.3 to $80 \mu \mathrm{M}$, and the detection limit is $0.05 \mu \mathrm{M}$. Moreover, the sensor exhibits good stability, reproducibility and high activity for electrochemical oxidation of caffeine. Thus, it is available for the quantitative analysis of caffeine in Oolong tea.

Keywords: Caffeine; Poly(diallyldimethylammonium chloride); Multi-walled carbon nanotube; Oolong tea; Electrocheimcal sensor

\section{FULL TEXT}

(C) 2017 The Authors. Published by ESG (www.electrochemsci.org). This article is an open access article distributed under the terms and conditions of the Creative Commons Attribution license (http://creativecommons.org/licenses/by/4.0/). 